\title{
1 Energy balance and environmental impact analysis of marine microalgal biomass \\ 2 production for biodiesel generation in a photobioreactor pilot plant
}
3 E. Sevigné Itoiz ${ }^{1,4, *}$, C. Fuentes-Grünewald ${ }^{2,3}$, C. M. Gasol ${ }^{1}$, E. Garcés ${ }^{2}$, E. Alacid ${ }^{2}$,
4 S. Rossi ${ }^{3} \&$ J. Rieradevall ${ }^{4}$

5

$6 \quad{ }^{1}$ Inèdit, Carretera de Cabrils, km. 2, IRTA, 08348 Cabrils, Spain

$7 \quad{ }^{2}$ Department of Marine Biology and Oceanography, Marine Science Institute, CSIC,

8 Passeig Marítim de la Barceloneta, 37-49 E-08003 Barcelona, Spain

$9{ }^{3}$ Institute of Environmental Science and Technology (ICTA), Universitat Autònoma de

10 Barcelona, (UAB) Building C Campus UAB - 08193 Cerdanyola del Vallés

11 (Barcelona), Spain.

$12{ }^{4}$ SOSTENIPRA, Department of Chemistry Engineering, Universitat Autònoma de

13 Barcelona (UAB) Building Q UAB - 08193 Cerdanyola del Vallès (Barcelona), Spain.

15 *Corresponding author: Tel: +34 9358137 60; fax: +34 935813331

16 E-mail address: eva.sevigne@uab.cat 
Abstract: A life cycle assessment (LCA) and an energy balance analysis of marine microalgal biomass production were conducted to determine the environmental impacts and the critical points of production for large scale planning. The artificial lighting and temperature conditions of an indoor bubble column photobioreactor (bcPBR) were compared to the natural conditions of an equivalent outdoor system. Marine microalgae, belonging to the dinoflagellate and raphidophyte groups, were cultured and the results were compared with published LCA data obtained from green microalgae (commonly freshwater algae). Among the species tested, Alexandrium minutum was chosen as the target marine microalgae for biomass production under outdoor conditions, although there were no substantial differences between any of the marine microalgae studied. Under indoor culture conditions, the total energy input for A. minutum was $923 \mathrm{MJ} \mathrm{kg}^{-1}$ vs. $139 \mathrm{MJ} \mathrm{kg}^{-1}$ for outdoor conditions. Therefore, a greater than $85 \%$ reduction in energy requirements was achieved using natural environmental conditions, demonstrating the feasibility of outdoor culture as an alternative method of bioenergy production from marine microalgae. The growth stage was identified as the principal source of energy consumption for all microalgae tested, due to the electricity requirements of the equipment, followed by the construction material of the bcPBR. The global warming category (GWP) was 6 times lower in outdoor than in indoor conditions. Although the energy balance was negative under both conditions, this study concludes with suggestions for improvements in the outdoor system that would allow up-scaling of this biomass production technology for outdoor conditions in the Mediterranean.

Keywords: Alexandrium minutum, Karlodinium veneficum, Heterosigma akashiwo, 


\section{INTRODUCTION}

43 The next decade will be crucial in solving many of the environmental issues of our

44 planet, especially those regarding the increase in greenhouse gases (GHG), water shortages, and the depletion of fossil fuels. Issues related to $\mathrm{CO}_{2}$ emissions and fossil fuel depletion are linked, due to the large amounts of $\mathrm{CO}_{2}$ released into the atmosphere from the industrial, transportation, and energy sectors [1]. To avoid further increases in GHG emissions and to increase the energy reserves of different countries, governments, policy stakeholders and research groups are investing in and developing projects related to the production of biofuels from terrestrial biomass feedstock, known as the "first generation" biodiesel, including corn, rapeseed, sunflowers, and sugarcane plants. There are advances in the production of "second generation" biodiesel, using residues from trees or lignocellulosic material as feedstock for bio-ethanol production. However, the use of these feedstocks for biodiesel production is controversial because the processing and commercialization of terrestrial plants are associated with several environmental and social problems, including a loss of biodiversity, increased freshwater consumption, higher prices of edible plants, and the resulting social inequalities [2]. Alternatively, one of the most promising feedstocks for the "third generation" of biodiesel production involve microalgae, due to their photosynthetic conversion efficiency, fast growth, sustainable biomass production, and high content of triacylglycerols (TAG), which is the oil that is commonly used as a raw material for biodiesel production [5],[6]. To date, freshwater microalgae have been the main microalgal species researched for biomass and biodiesel production purposes. Of particular interest are the green algae, or

64 Chlorophycean, including Chlorella vulgaris, Chlorella protothecoides, Chlamydomonas reinhardtii, and Neochloris oleoabundans, due to their high growth rates and their well-studied life cycle $[7,8]$. However, a drawback to their use is the 
permanent need for large quantities of freshwater in the continuous production of sufficient microalgal biomass, independent of the culture system. Use of sea/wastewater as the culture medium would significantly reduce the water footprint [9]. This implies the need to isolate seawater strains from the same place where they will later be grown. The efficient use of these strains requires that they have high TAG concentrations in addition to other energetically or commercially favorable cellular metabolites. Several advantages of the use of seawater as the medium for microalgae are that it leaves freshwater supplies free for other human and ecosystem uses, avoids ecological problems associated with the introduction of exotic microalgal species, maintains the system without any alteration to the local ecology, and avoids the loss of biodiversity [10]. The use of seawater microalgae strains allows the installation and operation of industrial scale plants in coastal countries, use non-arable land, and avoids or at least reduces freshwater consumption.

Based on these considerations, our group has explored the growth rates, lipid profiles, and TAG concentrations of various marine microalgal species and involved culturing the strains of interest in enclosed systems and improving these cultures for energetic purposes [12]. Most of the microalgae evaluated by our group in previous studies belong to the dinoflagellates and raphidophytes classes [12]. Dinoflagellates are well known because of their extensive bloom-forming proliferations in natural marine environments throughout the world [14],[15]; in terms of the production of biomass for bioenergy, this harmful trait becomes an opportunity and an advantage. Previous studies $[16],[17]$ determined that dinoflagellates and raphidophytes readily adapt to growth in enclosed systems and that their natural capacity of proliferation can be exploited to establish long-term biomass culture facilities in various coastal countries $[17,18]$. The 
92 because they can be isolated readily from local seawater spots around the world [14].

93 Alexandrium minutum is a tecate dinoflagellate with a high cell biovolume (> 2800

$94 \mu^{3}$ ) with a high biomass and lipid productivity. The dinoflagellate Karlodinium veneficum and the raphidophyte Heterosigma akashiwo are atecate cells and are advantagous in terms of lipid extraction by the ease of breaking the cells and avoidance of a higher energy input for the extraction of the lipids. [13].

The biotechnology used for biomass production from microalgae principally involves two types of culture configuration: open and enclosed systems. Open systems, including raceways or open ponds, have a low initial cost of construction and maintenance, with a relatively low volumetric productivity, and parameters including temperature, evaporation, and contamination cannot be totally controlled [5]. Enclosed systems, including horizontal photobioreactors, bubble columns, or flat panels, produce a higher volumetric biomass (13-fold greater than raceways or ponds), allow the growth of a single microalgal cell type (monoculture), and have fewer contamination problems than open systems. However, the initial cost of construction is higher for enclosed systems than for open systems [5]. The energy cost of microalgal biomass production in enclosed systems suffers from the current need for materials and procedures that require high amounts of energy, including the different plastics used in the construction of the photobioreactor in bubble column photobioreactors and the concrete needed for open pond systems. Electricity consumption during the microalgal growth stage (water, air pumping, $\mathrm{CO}_{2}$ injection, etc.) or in the filtration systems used to extract the biomass from the seawater in the dewatering stage is also high. Both open and enclosed systems are used to grow microalgae under autotrophic conditions, with sunlight as the energy source, nutrients obtained from a liquid medium, and inorganic carbon, as $\mathrm{CO}_{2}$, provided in pure form or as injected air with atmospheric $\mathrm{CO}_{2}$ concentrations. With 
117 these inputs, chemical energy is formed via photosynthesis [18]. Presently, most of the studies that use microalgae for biofuel purposes have been implemented in the lab or

119 pilot scale, pending industrial scaling to demonstrate the production feasibility $[7,8]$.

In this study, an enclosed system was chosen to achieve high marine microalgae

biomass production because it allows the control of abiotic parameters and its biomass

122 production per volumetric area is higher than in open systems. Additional considerations in establishing open system facilities are the high price of land in the Mediterranean area and the stable weather conditions in this area. The local strains of dinoflagellates and raphidophytes produce extensive natural proliferations in the Mediterranean basin [20], so these conditions were reproduced in controlled systems $[12,13]$, together with the same abiotic parameters and seawater encountered by natural populations, following the suggestion of "built around algae" facilities for long-term microalgal biomass production [21].

Life cycle assessment (LCA) is a tool that allows the potential impacts along the life cycle of a product, process, or activity to be evaluated. LCA studies in microalgal biomass production for biodiesel purposes are principally based on models or laboratory data; however, most of the data are assumptions or refer to a hypothetical system based on extrapolations from lab-scale studies [9],[22],[23]. In this study, data for the LCA were obtained from a previous study [18], in which microalgal cultures were run in a bubble column photobioreactor (bcPBR) pilot plant under controlled conditions

137 (indoors) and in a natural environment (outdoors). Energy balance is the key consideration in the design and development of a new methodology/feedstock aimed at energy production. Accordingly, measuring and evaluating the energy consumption of a newly proposed system simplifies improvements and facilitates increases in its efficiency. 
142 The aims of the present study can be defined as follows:

143 1) To determine the energy balance of dry marine microalgal production (A. minutum,

$144 K$. veneficum and $H$. akashiwo) in a bcPBR pilot plant under indoor and outdoor

145 conditions.

146 2) To evaluate and determine the principal environmental and energy impacts in the

147 production of marine microalgal biomass under artificial (indoor) and natural (outdoor)

148 conditions of temperature and lighting in a bcPBR pilot plant.

149 3) To assess the relative energy and environmental contributions of LCA stages, to

150 detect the weak also in addition to the critical points of an outdoor system, with the goal

151 of obtaining a viable and scalable design for an industrial-scale biodiesel facility.

152 4) To discuss the feasibility of microalgal biomass production facilities for biodiesel

153 generation in the Mediterranean basin using outdoor conditions without the need of

154 energy inputs using artificial light and temperature control.

\section{MATERIALS AND METHODS}

2.1 Description of the microalgal cultivation in the pilot plant

157 The study was conducted at the Institut de Ciències del Mar (ICM-CSIC), Barcelona, Spain, under ambient Mediterranean climate conditions (41 $23^{\circ} 16.5^{\prime \prime} \mathrm{N}$; 02 $2^{\circ} 10^{\prime} 11.71^{\prime \prime}$

E). Three species of microalgae, two belonging to Dinophyceae (AMP4 A. minutum and ICMB252 K. veneficum) and one to Raphidophyceae (ICMB830 H. akashiwo) were grown in bubble columns under indoor and outdoor environmental conditions.

The experimental design consisted of a bcPBR, which has a supporting structure of wood and polymethylmethacrylate tubes, as depicted in Figure 1. The polymethylmethacrylate tubes (height $=2.0 \mathrm{~m}$ and diameter $=0.15 \mathrm{~m}$ ) each had a volume of $33 \mathrm{dm}^{3}$. Three tubes were used for each microalgal species, both for indoor and outdoor conditions; therefore, the indoor system had a total workload of $0.297 \mathrm{~m}^{3}$ 
as did the outdoor system. The bcPBR was $2.65 \mathrm{~m}$ in length and $0.75 \mathrm{~m}$ in width. The

separation between the tubes was $0.11 \mathrm{~m}$, with a total surface utilized of $1.98 \mathrm{~m}^{2}$ and a volume-surface ratio of $0.15 \mathrm{~m}^{3} \mathrm{~m}^{-2}$. For both growth conditions, the microalgae were cultured in triplicate.

Under indoor conditions, the microalgal strains were grown in a temperature-controlled room at $20^{\circ} \mathrm{C} \pm 1^{\circ} \mathrm{C}$. All cultures were grown in filtered $(0.21 \mu \mathrm{m})$ seawater (salinity of $37 \mathrm{~kg} \mathrm{~m}^{-3}$ and neutral $\mathrm{pH}$ ) obtained from the ICM culture facilities and supplemented with a full L1-enriched medium without added silicates [24]. Pre-filtered air (Iwaki by a Qubitsystem $\mathrm{S} 151 \mathrm{CO}_{2}$ Analyzer) was injected from the bottom of the tubes at a flow of $50 \mathrm{c} \mathrm{m}^{3} \mathrm{~s}^{-1}$, which allowed gentle agitation inside the bubble column. For outdoors conditions, a bcPBR with the same layout, seawater salinity, $\mathrm{pH}$, injected air, and growth medium as used for the indoor conditions was placed on the terrace of the ICM-CSIC. The experiment started in mid November 2009 and was terminated at the end of May 2010 (autumn, winter, and spring in the northern hemisphere). Cultures were run in a semi-continuous mode because $50 \%$ of the biomass was harvested depending on the duplication time of each species (Figure 2). Throughout the experiment, light and temperature were recorded under the outdoor conditions from the Catalonia meteorological station net [25].

Figure 1. Photograph of the bubble column photobioreactor (bcPBR) under outdoor (left) and indoor (right) conditions.

188 To obtain dry biomass, the samples were centrifuged at $471 \mathrm{rad} \mathrm{s}^{-1}$ for $420 \mathrm{~s}$ in a Sigma 3-16 K centrifuge to separate the seawater from the microalgae. The supernatant water was discarded and a wet biomass pellet was recovered. 

conditions. + Indicates the harvest time of the culture.

2.2 Life cycle assessment (LCA) of the microalgal biomass production in a bcPBR pilot plant

The energy and environmental assessment of the proposed experimental design was carried out using the LCA methodology. The LCA evaluates the potential impacts along the life cycle of a product, process, or activity, from raw material extraction to production, use, and disposal [26]. The ISO 14040 provides guidance on the four steps of the LCA: goal and scope, inventory analysis, life cycle impact assessment, and life cycle interpretation.

\subsubsection{Functional unit and boundary system}

The functional unit of this study is the production under indoor and outdoor conditions of $1 \mathrm{~kg}$ of dry microalgal biomass from each of the species studied. The biomass obtained would be used for biodiesel production. Figure 3 depicts the studied system and its limits. The system includes all the steps necessary to obtain dry biomass from microalgae: culture medium production, bcPBR structure production, energy consumption during the filling and dewatering stages, growth of the microalgae (indoors and outdoors), and bcPBR maintenance (cleaning). Lipid extraction and transesterification are not considered in the limits of biomass production of this LCA.

Figure 3: Life cycle system of microalgal biomass production for biodiesel production

213 Table 1 shows the life cycle inventory and the data, which were collected and classified 214 throughout the experiment (November 2009 - May 2010). All data are expressed per 
215 functional unit, i.e., the production of $1 \mathrm{~kg}$ of dry microalgal biomass, except for the equipment, is expressed in terms of power. Table 2 details the dry biomass obtained per

217 liter [18].

218 Inflows to the system included equipment power $(\mathrm{kW})$, operating rates $\left(\mathrm{s} \mathrm{kg}^{-1}\right)$,

219 photobioreactor material (acrylic $\mathrm{kg} \mathrm{kg}^{-1}$ ), culture medium doses $\left(\mathrm{kg} \mathrm{kg}^{-1}\right)$, and seawater 220 consumption $\left(\mathrm{m}^{3} \mathrm{~kg}^{-1}\right)$. Outflows from the system were dry biomass $(\mathrm{kg})$ and the waste

221 seawater with $\mathrm{L} 1$ culture medium obtained following centrifugation $\left(\mathrm{kg} \mathrm{m}^{-3}\right)$. In the 222 dewatering process, $98.5 \%$ of the water is lost as a result of the centrifugation

223 dewatering [12]. The production inventory of the culture medium was taken from the

224 literature and the ecoinvent database [27],[28]. Data for the electricity was obtained

225 from the ecoinvent database as well [29].

226 The water and air needed for the experiment were supplied by general pumps located in

227 the ICM which in turn supply water and air to various experiments of the research center. The total energy consumption from the water pump was calculated from the hours of working required for the experiment and pump power. The same procedure was followed for the energy consumption of the dewatering, although specific equipment was used for the experiment. Air was pumped into a tank with a flow of 202 $\mathrm{dm}^{3} \mathrm{~s}^{-1}$ and then was provided to the experiment with a flow of $50 \mathrm{~cm}^{3} \mathrm{~s}^{-1}$. The total pump energy consumption was calculated considering time for tank filling and air pump power.

The total volume of the chamber used is greater than the volume required for this experiment; therefore, the total energy consumption of the chamber $\left(28.8 \mathrm{~m}^{3}\right)$ was adapted to the volume of the growing tubes $\left(0.3 \mathrm{~m}^{3}\right)$, taking into account the space needed between the tubes (the volume fraction is $14 \%$ ). The same procedure used for the chamber was adopted to determine the energy consumption due to the fluorescent 
lights. To calculate the bioenergy production from the biomass obtained the lipid extraction and the oil transesterification should be considered. A production rate of $25 \%$ lipids was measured for each microalgal species in a previous study $[13,19]$ and a transformation of $90 \%$ was considered.

Table 1. Life cycle inventory of biomass production for three marine microalgal species cultured under indoor and outdoor conditions

Table 2. Dry biomass per liter for each microalgal species and growth system

2.2.2.1 Assumptions for life cycle inventory

In the life cycle inventory the following assumptions were made:

\subsubsection{Energy assessment}

Simapro 7.1.8 software and the "Cumulative Energy Demand v 1.4" method were used in the energy assessments at all stages of the LCA. This method was used to estimate 
the direct energy consumption, including the use of seawater and the freshwater needed

266 for the maintenance, production of culture medium and the production of bcPBR. In

267 addition, the net energy balance was determined, calculated as the difference between

268 energy output and energy input.

2692.3 Sensitivity analysis

270 A sensitivity analysis was conducted using the variables of energy consumption and

271 lipid content of dry biomass to observe when positive balances would be achieved. The

272 analysis used results obtained for outdoor production from A. minutum because this

273 dinoflagellate species presented the best energy results. Five scenarios where defined as

274 A, B, C, D and E. The base case for all results reported in this LCA is calculated for the 275 algae composition of $25 \%$ lipids so the percentage of lipid content was increased at 276 intervals of $10 \%$ from the base case represented by scenario A. Energy consumption 277 was reduced at intervals of $50 \%$ from the base results obtained in the study. Both

278 variables were modified in each scenario, so in scenario B the energy consumption was

279 reduced by $50 \%$ over scenario A and lipid content increased by $10 \%$; in scenario C

280 energy consumption was reduced by $50 \%$ over scenario B and lipid content was

281 increased again by 10\%; and so on for scenarios D and E.

282 3. RESULTS

283 The following sections describe the energy balances obtained for indoor and outdoor 284 production systems and the energy and environmental assessment of the different stages 285 considered in the LCA. Finally, the data from the sensitivity analyses determined from 286 the best results (A. minutum) is presented.

$287 \quad 3.1$ Energy results

288 Table 3 lists the total energy consumption by each species of marine microalgae for 289 both production systems and the output of bioenergy production from microalgae based 
on the inventory and the assumptions described in section 2.2.2. The energy balances obtained are also presented. The results are expressed in MJ per kg of dry microalgae species biomass.

\section{Table 3. Energy consumption, output and balance per kg of dry biomass for each} life cycle stage and for each microalgal species and growth system

\subsubsection{Energy results of production systems}

First, it is observed from Table 3 that negative balances were obtained for both productions systems. In addition, the energy balance results demonstrated large differences between the indoor and outdoor systems in contrast to the biomass results displayed in Table 2, in which the two systems did not differ substantially. The outdoor system consumed significantly less energy than the indoor system with differences between 721 and $783 \mathrm{MJ} \mathrm{kg}^{-1}$. Specifically, A. minutum grown in the outdoor system had the best energy balance $\left(-139 \mathrm{MJ} \mathrm{kg}^{-1}\right)$ while indoor production of this same microalgae had the worst balance $\left(-923 \mathrm{MJ} \mathrm{kg}^{-1}\right)$.

\subsubsection{Energy results of microalgae}

Minor differences were found for the energy results of the different microalgal strains grown in the same production system. In the case of outdoor production, energy consumption differences were less than $7.5 \%$ and for indoor production the energy demands differed by less than $6.0 \%$. This means that for each type of microalgae and for both systems, biomass production was robust, and in future experiments and applications any microalgal species could be used.

\subsubsection{Energy results of life cycle stages}

The analysis of life cycle stages of both types of production and species indicated that the largest contributors to the energy demand were the microalgal growth and the construction of the bcPBR stages. 
315 In the indoor system, the growing life stage required high energy demands for light and temperature maintenance, which need to be artificially provided and controlled to maintain constant environmental conditions for growth (values highlighted in gray in Table 3) and using more than $85 \%$ of the electricity consumption of the entire system. The elimination of these operations reduces the overall electricity consumption by $90 \%$, as observed in the outdoor system, in which temperature and light were provided naturally, with no need for additional electricity input. However, the outdoor system air pumping involves considerable electricity consumption in the growth stage, approximately $60 \%$ of the entire system, constituting an energy demand of approximately $90 \mathrm{MJ}$. Notably that the equipment used for lighting, temperature and air pumping at the growth stage was adapted and not specially designed for the experiment, the ecodesign of the equipment could significantly reduce the electricity consumption and therefore improve the energy balance. In addition, the production of the bcPBR involves a significant energy demand in both systems because the chosen material has a high energy requirement in its production. The polymethylmethacrylate tubes were chosen because they allow a good light penetration for photosynthesis activity and prevent the aging of the material by the action of UV rays. The replacement of this material by other with same characteristics or the bcPBR ecodesign could contribute to reduce the energy inputs and improve the energy balances.

Other stages including dewatering, water consumption or L1 culture production to promote microalgal growth involve lower energy consumption in both systems; however, they should be considered in further research.

\subsection{Environmental results}

The environmental impacts of bioenergy production per functional unit were determined for ten impact categories. The total environmental impact by production system and by 
type of marine microalgae, particularly compared with the global warming category, is presented followed by an evaluation of the relative contributions of the life cycle stage.

\subsubsection{Total environmental impacts}

343 For all impact categories and microalgal species, outdoor systems had lower

344 environmental impacts (see Table 4). Specifically, A. minutum outdoor production had 345 the lowest environmental impact in all categories (marked in black in Table 4). By contrast, A. minutum indoor production had the highest impact (indicated in gray in Table 4) for all categories. The outdoor system had significantly fewer environmental impacts than the indoor systems with differences between $85 \%$ and $88 \%$, indicating that in environmental terms the outdoor system had superior results and it is therefore presented as the preferable choice. Similar to energy results, there were few differences between the types of microalgae, for outdoor and indoor systems the environmental impacts differ less than $6 \%$ between them in all impact categories.

\section{Table 2. Environmental impacts for microalgal species and impact category}

Compared with the global warming (GWP) category, the indoor system production yielded an average of $146.3 \mathrm{~kg} \pm 4 \mathrm{~kg}$ of $\mathrm{CO}_{2}$ eq. per functional unit (kg of dry biomass). The outdoor production in the same category resulted in an average of 23.24

$357 \mathrm{~kg} \pm 0.7 \mathrm{~kg}$ of $\mathrm{CO}_{2}$ eq. Thus, the GWP was 6 times lower under outdoor than indoor conditions.

\subsubsection{Environmental impacts of life cycle stage}

To analyze in greater detail the environmental impacts by impact category, it is necessary to assess the impacts by life cycle stages. Figure 4 shows the relative contributions of the life cycle stages of $A$. minutum indoor production which has the worst environmental impact results. The higher environmental impacts under indoor conditions for A. minutum were due to the microalgal growth stage, which accounted for 
more than $95 \%$ of all of the environmental impacts and is a totally function of electricity consumption, i.e., temperature, light conditions requirements and air pumping. The impacts are mainly due to the electricity production which depends on the Spanish energy mix considered which had a contribution of $57 \%$ fossil fuel energy and $20 \%$ renewable energy. The relative contribution of filling and centrifugation were less than $2 \%$ and were dependent on the electricity consumption and water and nutrient consumption for the filling stage; thus, more than $96 \%$ of all of the environmental impacts are due to electricity consumption and therefore due to the Spanish mix. A change in the contributions of fossil energies would contribute to decrease the environmental impacts. The remaining environmental impacts from the indoor production were a consequence of the bcPBR production. A material change could involve a reduction of the environmental impacts.

\section{Figure 4. Relative contributions of different life stages of $A$. minutum under indoor} conditions

As was the case for the indoor production of A. minutum, the outdoor production of $H$. akashiwo had the worst environmental results; therefore, its breakdown of life cycle stages was chosen to analyze the environmental impacts of the outdoor system and to define the principal environmental impact. The results and its relative percentages for each life cycle stages are depicted in Figure 5. The electric consumption is considerably lower in this system; therefore, the impacts due to other stages implied a higher relative contribution for certain categories. This demonstrates that these stages are also a source of impacts and should be considered.

Figure 5. Relative contribution of different life cycle stages of $\boldsymbol{H}$. akashiwo under outdoor conditions. 
The electricity consumption yielded results of 71\% (AD) and 95\% (ODP-TE) in all environmental impacts where the growth stage accounted for $65 \%$ (AD) and $87 \%$ (ODP-TE) and the centrifuge represented approximately $7 \%$ of impacts in all categories.

As for the indoor system, these impacts are due to the energy mix considered. The production of the bcPBR constitutes the second stage with higher impacts, and as in the indoor production, the consumption of fossil fuels implies that in AD, AC, E, GWP and PO, the contribution was between $14 \%$ and $24 \%$ indicating again that the reactor material substitution could involve great environmental improvements.

The lowest environmental impacts in all of the categories were during the stage of filling which depends on electricity for pumping, water and nutrients consumption. Figure 6 presents their relative contributions showing that the L1 culture consumption had the highest contribution in the categories of E and GWP due to the nutrient consumption of nitrogen or phosphorous.

Figure 6. Relative contribution of electricity, water and L1 culture consumption of

\section{H. akashiwo under the outdoor conditions during the filling stage}

\subsection{Sensitivity analysis}

Sensitivity analysis of the outdoor production of A. minutum was performed by changing the energy consumption and lipid content of the dry biomass. Table 5 displays the results obtained for the scenarios defined. Positive balances were obtained for scenarios $\mathrm{D}$ and $\mathrm{E}$, which implies an energy reduction of $88 \%$ from the base results presented in scenario A and a content lipid of 55\%. These results demonstrate that great efforts should be made to achieve positive balances of this production system. However, as noted in section 3.1, there is a great potential for energy reduction if ecodesign and specifically adapted equipment is used for the microalgae production and/or if the bcPBR or the material itself is replaced. The environmental impacts of scenario D 
414 would be reduced by $63-84 \%$; so the emissions of $\mathrm{CO}_{2}$ eq. would be $8.2 \mathrm{~kg}$ per

415 functional unit.

416 Table 5. Sensitivity analysis after modifying energy consumption and lipid content

417 for scenarios A, B, C, D and E

418 4. DISCUSSION

419 The production of microalgae in an outdoor rather than an indoor system results in a

420 slight decrease in biomass production; nevertheless, it involves a significant decrease in

421 the total energy consumption, thus outdoor systems are presented as a preferable option.

422 This study was conducted on experimental data from a pilot plant and a key aspect was

423 that the equipment used was not specifically designed for the experiment. However, this

424 is the first step to properly scale an experiment and the joint analysis of production,

425 energy and environmental impacts allows us to establish what the weakest points are on

426 which further research or greater effort must be applied. The results of the pilot plant

427 production indicate that outdoor production is possible and that the differences are notably small with controlled productions. However, future studies should take into account that biomass productivities in outdoor photobioreactors naturally illuminated would depend on the prevailing weather conditions in a particular locality [31]. Under Mediterranean climate conditions, our outdoor production system yielded similar or superior results as obtained for green algae in others studies based on the same geographical area [32,[33], and the differences between the marine microalgal species studied in this study were so small that the production of any of them would be possible. In recent years, many LCA and energy balance studies on the microalgae production for energetic purposes have been conducted [34-43]; however, there is an enormous variety of microalgae species that can be used to produce biodiesel and many different methods of microalgal cultivation. In addition, the life cycle stages included in each study may 
vary, thus, while certain studies have analyzed the entire cycle [34],[41]] others have only considered the culture process [38]. The results of several of these studies are presented in Table 6. However, due to methodological and life cycle differences, general comparisons and extrapolations are difficult.

\section{Table 6. Schemes of various LCA studies of bioenergy from microalgae}

444 The energy assessment indicates negative balances for both indoor and outdoor production systems; however, for the latter, positive balances can be gained by reducing energy consumption. In addition, for all the studies complied in Table 5 [37]-[40], negative balances are obtained except for [38] when raceway pond and flat-plate PBR are considered. These types of reactors consume considerably less energy than tubular PBRs [44],[45] or open ponds [40], thus an alternative strategy to decrease energy consumption would be to use an outdoor system based on a raceway pond inside a greenhouse. Nonetheless, in places in which evaporation is high, raceway ponds require more frequent water pumping than tubular bioreactors [41], which would increase energy consumption, and this needs to be taken into consideration. In addition, raceway or open ponds should be implemented in those countries with extensive non-arable or inexpensive land (e.g., North African countries). In contrast, in those countries in which high land prices limit the system (EU Mediterranean countries), bcPBRs or other enclosed systems is a reasonable choice. In addition, the production of bcPBR has been observed to be the second highest source of energy consumption due to material election. As indicated by [40], one of the disadvantages of such reactors is that their construction requires sophisticated materials. Thus, innovations and ecodesign in the layout and construction materials would significantly reduce the energy consumption associated with its production and decrease the overall energy requirements. These innovations include the combination of advanced designs of synthetic bags floating 
partially submerged in an artificial pond (a combination of open and enclosed systems), or a single reactor module consisting of one large translucent plastic bag containing multiple vertical panels [21].

467 Downstream processing, i.e., dewatering and lipid extraction, have been observed as important stages and should be considered in energy balances [46],[47]. In a previous study [39], dewatering constitutes the largest energy input, consuming $54 \mathrm{MJ}$ per $\mathrm{kg}$ of dry biomass due to natural gas consumption. However, a different study [40] carried out a comparative LCA on dry and wet dewatering, and the dry process consumed 4.7 MJ per $\mathrm{kg}$ of dry biomass due to a centrifuge (similar to our study) in which energy consumption resulting from dewatering is 6 and $8 \mathrm{MJ} \mathrm{kg}^{-1}$ for outdoor and indoor systems, respectively. The lipid extraction is not discussed; however, certain authors found the highest energy consumption as a result of this stage [42],[43]. Further studies must be conducted to establish the best options for the dewatering alternatives and lipid extraction processes.

The use of a culture medium to promote microalgal growth is the life cycle stage with the lowest energy consumption, which contrasts with results found in a previous study [37] and with terrestrial crops for biofuel purposes, in which energy consumption related to crop fertilization and to production could be the highest in the entire cycle. Fertilizer manufacture itself amounts to $46 \%$ in the establishment of the crop and $32 \%$ in the first cycle [48] for a LCA conducted of a Populus spp. crop.

Relative to environmental impacts, the use of microalgae production has been promoted in part as a means to reduce $\mathrm{CO}_{2}$ emissions and improve sustainability [49],[50]. Certain previously reported LCA studies have also conducted environmental analyses [39],[41]. The environmental results of our study demonstrated that main environmental impacts are due to electricity consumption and for the global warming category (GWP) the 
emission of $0.16 \mathrm{~kg} \mathrm{CO}_{2}$ eq. per MJ were found. Lower results of $0.07 \mathrm{~kg}$ and $0.06 \mathrm{~kg}$ per MJ were reported by other studies [39,41]. However, results from the sensitivity analysis demonstrate that positive balances could be achieved by reducing the GWP to $0.06 \mathrm{~kg} \mathrm{MJ}^{-1}$.

Finally, there is a need to standardize data quality for the inventory used, especially for the purpose of comparing studies. Our study used experimental data, whereas in most cases, the data were obtained from a bibliographic inventory or were extrapolated from industrial processes used for other modes of generic biofuel production. In this sense, the energy balances obtained may not be consistent.

\section{CONCLUSIONS}

In Mediterranean outdoor conditions, marine microalgae production for biodiesel is a good option and a feasible route to obtain bioenergy. We recommend that production and research under indoor conditions be rejected based on the energy results obtained. However, for outdoor systems, efforts should be made to decrease energy consumption. As revealed herein, the highest energy consumption occurs during the growing stage due to the mechanical requirements of the pumps and the need for air injection. Thus, for industrial scale improvements, more efficient equipment is needed. In the same manner, more energy-conserving bcPBR material or its eco-design could significantly reduce energy consumption. Any of the three microalgae analyzed can be cultivated and exploited on a large scale as there were no substantial differences in biomass production between them. In addition, the use of any of these marine microalgae leaves freshwater for other human uses and thus helps to overcome the critical issue of freshwater consumption in the production of microalgae. This would improve the feasibility of 
512 bioenergy in terms of its large scale production and the scarcity of freshwater in the

513 Mediterranean area.

514 Other experiments should be conducted to assess productivities in Mediterranean

515 climates for spring-summer periods to evaluate whether higher productivities are

516 achieved and less energy is needed. Besides biodiesel production, additional research is

517 needed to identify the coproducts for bioenergy and other purposes.

\section{Acknowledgements}

519 The authors would like to thank to Comisión Nacional de Investigación Ciencia y

520 Tecnología (CONICYT) from Chile for supporting the scholarship "Beca de Gestión

521 Propia," which finances the PhD studies of C. Fuentes-Grünewald; and to Spanish

522 Ministry of Science and Innovation for supporting the work of E. Garcés and S. Rossi

523 by the Ramon and Cajal award. The authors would like also to thank S. Fraga for

524 providing the clonal culture AMP4, Laura del Río and Xavi Leal for their help with the

525 experiments, and the Zona Acuarios Experimentales (ZAE) of the ICM-CSIC for the

526 use of their facilities. The authors would like also to thank to project Ecotech Sudoe

527 SOE2/P2/E377 for its financial support.

528 


\section{REFERENCES}

[1] Bates BC, Kundzewicz ZW, Wu S, Palutikof JP, Eds. Climate Change and Water. Technical Paper of the Intergovernmental Panel on Climate Change. Geneva: IPCC Secretariat, 2008. 210 p.

[2] Dauvergne P, Neville K. Forests, food, and fuel in the tropics: the uneven social and ecological consequences of the emerging political economy of biofuels. $\mathbf{J}$ Peasant Stud 2010; 37(4): 631-60

[3] Dufey A. Biofuels production, trade and sustainable development: emerging issues. London: International Institute for Environment and Development; 2006. 62 p

[4] Koh LP. Potential habitat and biodiversity losses from intensified biodiesel feedstock production. Conserv Biol 2007; 21(5): 1373-5

[5] Chisti Y. Biodiesel from microalgae. Biotechnol Adv 2007; 25(3): 294-306

[6] Hu Q, Sommerfeld M, Jarvis E, Ghirardi M, Posewitz M, Seibert M, et al. Microalgal triacylglycerols as feedstocks for biofuel production: perspectives and advances. Plant J 2008; 54(4): 621-39

[7] Rodolfi L, Chini Zitella G, Bassi N, Padovani G, Bionde N, Bonini G, et al. Microalgae for Oil: Strain Selection, Induction of Lipid Synthesis and Outdoor Mass Cultivation in a Low-Cost Photobioreactor. Biotechnol Bioeng 2008; 102(1): $100-12$

[8] Liang Y, Sarkany N, Cui Y. Biomass and lipid productivities of Chlorella vulgaris under autotrophic, heterotrophic and mixotrophic growth conditions. Biotechnol Lett 2009; 31(7): 1043-49

[9] Yang J, Xu M, Zhang X, Hu Q, Sommerfeld M, Chen Y. Life-cycle analysis on biodiesel production from microalgae: Water footprint and nutrients balance. Bioresource Technol 2011; 102(1): 159-65 
554 [10] Griffiths M, Harrison S. Lipid productivity as a key characteristic for choosing

555 algal species for biodiesel production. J Appl Phycol 2009; 21(5): 493-507

556 [11] Grobbelaar JU. Microalgal biomass production: challenges and realities.

557 Photosynth Res 2010; 106(1): 135-44

558 [12]Fuentes-Grünewald C, Garcés E, Rossi S, Camp J. Use of the dinoflagellate

$559 \quad$ Karlodinium veneficum as a sustainable source of biodiesel production. J Ind

$560 \quad$ Microbiol Biot 2009; 36(9): 1215-24

561 [13]Fuentes-Grünewald C, Garcés E, Alacid E, Sampedro N, Rossi S, Camp J.

562 Improvement of lipid production in the marine strains Heterosigma akashiwo and

$563 \quad$ Alexandrium minutum utilizing abiotic parameters. J Ind Microbiol Biot 2011;

$564 \quad 39(1): 207-16$

565 [14] Anderson DM. Toxic algal blooms and red tides: A global perspective. In: Okaichi

566 T, Anderson DM, Nemoto T, editors. Red tides: Biology, environmental science,

567 and toxicology. New York: Elsevier; 1989. p 11-16.

568 [15] Smayda TJ. Harmful algal blooms: Their ecophysiology and general relevance to

569 phytoplankton blooms in the sea. Limnol Oceanogr 1997; 42 (5 Pt 2): 1137-53

570 [16] Gallardo-Rodríguez JJ, Mirón AS, Camacho FG, García MC, Belarbi EH, Chisti Y,

571 et al. Causes of shear sensitivity of the toxic dinoflagellate Protoceratium

572 reticulatum. Biotechnol Progr 2009; 25(3):792-800

573 [17]Parker NS, Negri AP, Frampton DMF, Rodolfi L, Tredici MR, Blackburn SI.

$574 \quad$ Growth of the toxic dinoflagellate Alexandrium minutum (dinophyceae) using high

575 biomass culture systems. J Appl Phycol 2002; 14(5): 313-24

576 [18]Fuentes-Grünewald C, Garcés E, Alacid N, Rossi S, Camp J. Biomass and lipid

577 production of dinoflagellates and raphidophytes in indoor and outdoor

578 photobioreactors. Mar Biotechnol. Forthcoming 2012 
579 [19]Huang GH, Chen F, Wei D, Zhang XW, Chen G. Biodiesel production by

580 microalgal biotechnology. Appl Ener 2010; 87(1): 38-46

581 [20] Anglès S, Jordi A, Garcés E, Basterretxea G, Palanques A. Alexandrium minutum

582 resting cyst dynamics in a confined site. Deep-Sea Res Pt II 2010; 57(3-4): 210-21

583 [21] Morweiser M, Kruse O, Hankamer B, Posten C. Developments and perspectives of

584 the photobioreactors for biofuel production. Appl Microbiol Biotechnol 2010;

$585 \quad$ 87(4): 1291-301

586 [22]Batan L, Quinn J, Willson B, Bradley T. Net Energy and Greenhouse Gas Emission

587 Evaluation of Biodiesel Derived from Microalgae. Environ Sci Technol 2010;

$588 \quad 44(20): 7975-80$

589 [23] Collet P, Hélias A, Lardon L, Ras M, Goy RA, Steyer JP. Life-cycle assessment of $590 \quad$ microalgae culture coupled to biogas production. Bioresource Technol 2011;

591 102(1): 207-14

592

593

594

595

596

597

598

599

600

601

602

603

[24] Guillard RRL, Hargraves PE. Stichochrysis immobilis is a diatom, not a chyrsophyte. Phycologia 1993; 32(3): 234-6

[25]Xarxa d'Estacions Metereologics de Catalunya, Barcelonès, Estació Barcelona-El Raval [Internet]. Barcelona (Spain): Servei Meteorologic de Catalunya. Generalitat de Catalunya; 2005 [cited March 2010]. Available from http://www.meteo.cat/xema/AppJava/SeleccioPerComarca.do

[26] ISO 14.040. Environmental management-life cycle assessment-Principles and framework. International Organization of Standardization, Geneva. Switzerland. (2006).

[27]Classen M, Althaus H, Blaser S, Doka G. Life cycle inventories of metals. Dünbendorf (Switzerland): Swiss Centre for Life Cycle Inventories; 2007. Report. No. 6 
[28]Frischknecht $\mathrm{R}$ et al. Implementation of Life Cycle Impact Assessment Methods. Dünderdorf (Switzerland): Swiss Centre for Life Cycle Inventories; 2007. 151 p. Report No. 3

[29]Dones R et al. Life Cycle Inventories of Energy Systems: results of current systems in Switzerland and other UCTE Countries. Dünderdorf (Switzerland): Swiss Centre for Life Cycle Inventories; 2007. 185 p. Report No.5

[30]Lechón Y, Cabal H, Lago C, Izquierdo L, de la Rúa C, Sáez R. Análisis de ciclo de vida de combustibles alternativos para el transporte. Fase II: análisis de ciclo de vida comparativo del biodiesel y el diesel. Madrid (Spain): Centro de publicaciones, Secretaria General Técnica, Ministerio de Medio Ambiente; 2006.

$$
16 \mathrm{p} \text {. }
$$

[31]Ugwu CU, Aoyagi H, Uchiyama H. Photobioreactors for mass cultivation of algae. Bioresource Technol 2008; 99(10): 4021-8

[32] Kromkamp JC, Beardall J, Sukenik A, Kopeck J, Masojidek J, Bergeijk S, Gabai S, Shaham E, Yamshon A. Short-term variations in photosynthetic parameters of Nannochloropsis cultures grown in two types of outdoor mass cultivation systems. Aquat Microb Ecol 2009; 56: 309-22

[33] Chen CY, Yeh KL. Cultivation, photobioreactor design and harvesting of microalgae for biodiesel production: A critical review. Bioresource Technol 2011; 102(1): 71-81

[34] Campbell PK, Beer T, Batten D. Life cycle assessment of biodiesel production from microalgae in ponds. Bioresource Technol 2011; 102(1): 50-6

[35]Clarens AF, Resurrección EP, White MA, Colosi LM. Environmental life cycle comparison of Algae to other bioenergy feedstocks. Envir Sci Technol 2010; 44(5): 1813-19 
[36]Ehimen EA. Energy Balance of Microalgal-derived Biodiesel. Energ Source Part A 2010; 32(12): 1111- 20

[37] Razon LF, Tan RR. Net energy analysis of the production of biodiesel and biogas from the microalgae: Haematococcus pluvialis and Nannochloropsis. Appl Energ 2011; 88(10): 3507-14

[38] Jorquera O, Kiperstol A, Sales EA, Embiruçu M, Ghirardi ML. Comparative energy life-cycle analyses of microalgal biomass production in open ponds and photobioreactors. Bioresource Technol 2010; 101(4): 1406-13

[39] Sander K, Murthy GS. Life cycle analysis of algae biodiesel. Int J Life Cycle Ass 2010; 15(7): 704-14

[40] Xu L, Brilman D, Withag J, Brem G, Kersten S. Assessment of a dry and a wet route for the production of biofuels from microalgae: Energy balance analysis. Bioresource Technol 2011; 102(8): 5113-22

[41] Stephenson AL, Kazamia E, Dennis JS, Howe CJ, Scott SA, Smith AG. Life-cycle Assessment of potential Algal Biodiesel Production in the United Kingdom: A Comparison of Raceways and Air-lift Tubular Bioreactors. Energ Fuels 2010; 24(7): 4062-77

[42] Khoo HH, Sharratt PN, Das P, Balasubramanian RK, Naraharisetti PK, Shaik S. Life cycle energy and $\mathrm{CO}_{2}$ analysis of microalgae-to-biodiesel: preliminary results and comparisons. Bioresource Technol 2011; 102(10): 5800-7

[43]Lardon L, Hélias A, Sialve B, Steyer J-P, Bernard O. Life-cycle assessment of biodiesel production from microalgae. Envir Sci Tech 2009; 43(17): 6475-81

[44]Lehr F, Posten C. Closed photo-bioreactors as tools for biofuel production. Curr Opin Biotechnol 2009; 20(3): 280-85 
653

654

655

656

657

658

659

660

661

662

663

664

665

666

667

668

669

670

[45] Sierra E, Acién FG, Fernández JM, García JL, González C, Molina E. Characterization of a flat plate photobioreactor for the production of microalgae. Chem Eng J 2008; 138(1-3): 136-47

[46] Scott SA, Davey MP, Dennis JS, Horst I, Howe CJ, Lea-Smith DJ, Smith AG. Biodiesel from algae: challenges and prospects. Curr Opin Biotech 2010; 21(3): $277-86$

[47]Molina Grima E, Belarbi EH, Acién Fernandez FG, Robles Medina A, Chisty Y. Recovery of microalgal biomass and metabolites: process options and economics. Biotechnol Adv 2003; 20(7-8): 491-515

[48] Gasol CM, Gabarrell X, Anton A, Rigola M, Carrasco J, Ciria P, et al. LCA of populus spp. bioenergy system compared with Brassica carinata energy crop and natural gas in regional scenario. Biomass Bioenerg 2009; 33(1): 119-29

[49] Lee DH. Algal biodiesel economy and competition among bio-fuels. Bioresource Technol 2011; 102(1): 43-9

[50] Singh A, Irving Olsen S. A critical review of biochemical conversion, sustainability and life cycle assessment of algal biofuels. Applied Energ 2011; 88(10): 3548-55 
Table 1: Life cycle inventory of biomass production per functional unit for three marine microalgal species cultured under indoor and outdoor conditions

\begin{tabular}{|c|c|c|c|c|c|c|c|c|c|c|c|c|c|c|c|c|c|c|c|}
\hline \multicolumn{18}{|c|}{ INPUT } & \multicolumn{2}{|c|}{ OUTPUT } \\
\hline Struct & \multicolumn{6}{|c|}{ Filling } & \multicolumn{6}{|c|}{ Growing of microalgae } & \multirow{2}{*}{\multicolumn{2}{|c|}{$\begin{array}{l}\text { Dewatering } \\
\text { Centrifuge }\end{array}$}} & \multirow{2}{*}{\multicolumn{3}{|c|}{$\begin{array}{c}\text { Maintenance } \\
\text { Washing }\end{array}$}} & \multirow{3}{*}{$\begin{array}{c}\text { Prod. } \\
\text { Bio } \\
\text { kg }\end{array}$} & \multirow{3}{*}{$\frac{\text { WSW }}{\text { WSW }}$} \\
\hline $\mathrm{bcPBR}$ & \multicolumn{2}{|c|}{ Water pump } & \multirow{2}{*}{$\frac{S W}{\mathbf{m}^{\mathbf{3}}}$} & \multicolumn{3}{|c|}{ Nutrient L1 } & \multicolumn{2}{|c|}{ Chamber } & \multicolumn{2}{|c|}{ Air pump } & \multicolumn{2}{|c|}{ Fluorescence } & & & & & & & \\
\hline kg & $\mathbf{k W}$ & $\mathbf{s}$ & & $\mathbf{A}(\mathbf{k g})$ & $\mathbf{B}(\mathbf{k g})$ & $\mathbf{C}(\mathbf{k g})$ & $\mathbf{k W}$ & $\mathbf{s}$ & $\mathbf{k W}$ & $\mathbf{s}$ & $\mathbf{k W}$ & $\mathbf{s}$ & $\mathbf{k W}$ & $\mathbf{s}$ & $\mathbf{m}^{3}$ & $\mathbf{k W}$ & $\mathbf{s}$ & & \\
\hline 0.2 & 0.01 & $4.4 \mathrm{E}+04$ & 0.8 & $4.3 \mathrm{E}-03$ & $2.8 \mathrm{E}-03$ & $1.0 \mathrm{E}-06$ & 0.5 & $1.2 \mathrm{E} 06$ & 0.02 & $2.4 \mathrm{E} 6$ & 0.13 & $1.2 \mathrm{E} 06$ & 0.46 & $1.3 \mathrm{E} 4$ & 0.05 & 0.42 & $6.7 \mathrm{E} 3$ & 1.0 & 0.8 \\
\hline 0.3 & 0.01 & $5.6 \mathrm{E}+04$ & 1.0 & 4.6 E-03 & $3.6 \mathrm{E}-03$ & $1.0 \mathrm{E}-06$ & 0.0 & 0.0 & 0.02 & $3.1 \mathrm{E} 6$ & 0.0 & 0.0 & 0.46 & $1.8 \mathrm{E} 4$ & 0.06 & 0.42 & $8.7 \mathrm{E} 3$ & 1.0 & 1.0 \\
\hline 0.2 & 0.01 & $4.6 \mathrm{E}+04$ & 0.8 & $5.6 \mathrm{E}-03$ & $3.6 \mathrm{E}-03$ & $1.0 \mathrm{E}-06$ & 0.5 & $1.3 \mathrm{E} 6$ & 0.02 & $2.6 \mathrm{E} 6$ & 0.13 & $1.3 \mathrm{E} 6$ & 0.46 & $1.4 \mathrm{E} 4$ & 0.05 & 0.42 & $7.1 \mathrm{E} 3$ & 1.00 & 0.8 \\
\hline 0.3 & 0.01 & $5.3 \mathrm{E}+04$ & 1.0 & $5.2 \mathrm{E}-03$ & 3.4 E-03 & $1.0 \mathrm{E}-06$ & 0.0 & 0.0 & 0.02 & $3.0 \mathrm{E} 6$ & 0.0 & 0.0 & 0.46 & $1.6 \mathrm{E} 4$ & 0.06 & 0.42 & $8.1 \mathrm{E} 3$ & 1.00 & 0.9 \\
\hline 0.2 & 0.01 & $4.5 \mathrm{E}+04$ & 0.8 & $4.5 \mathrm{E}-03$ & 2.9 E-03 & $1.0 \mathrm{E}-06$ & 0.5 & $1.3 \mathrm{E} 6$ & 0.02 & $2.5 \mathrm{E} 6$ & 0.13 & $1.3 \mathrm{E} 6$ & 0.46 & $1.4 \mathrm{E} 4$ & 0.05 & 0.42 & $7.0 \mathrm{E} 3$ & 1.00 & 0.8 \\
\hline 0.3 & 0.02 & $5.6 \mathrm{E}+04$ & 1.0 & 5.5 E-03 & 3.5 E-03 & $1.0 \mathrm{E}-06$ & 0.5 & 0.0 & 0.02 & $3.1 \mathrm{E} 6$ & 0.0 & 0.0 & 0.46 & $1.7 \mathrm{E} 4$ & 0.05 & 0.42 & $8.6 \mathrm{E} 3$ & 1.00 & 1.00 \\
\hline
\end{tabular}

A: fertilizers N/P/K, B: metals, C: vitamins 
Table 2. Dry biomass per liter for each microalgal specie and growth system

\begin{tabular}{cc|cc|cc}
$\begin{array}{c}\text { Heterosigma akashiwo } \\
\left(\mathbf{g L}^{-\mathbf{1}}\right)\end{array}$ & \multicolumn{2}{c}{$\begin{array}{c}\text { Alexandrium minutum } \\
\left(\mathbf{g L}^{-\mathbf{1}}\right)\end{array}$} & \multicolumn{2}{c}{$\begin{array}{c}\text { Karlodinium Veneficum } \\
\left(\mathbf{g L}^{-\mathbf{1}}\right)\end{array}$} \\
\hline Indoor & Outdoor & Indoor & Outdoor & Indoor & Outdoor \\
1.25 & 0.97 & 1.18 & 1.03 & 1.2 & 0.98 \\
& & & & &
\end{tabular}


Table 3. Energy consumption, output and balance per kg of dry biomass for each life cycle stage and for each microalgal species and growth system

\begin{tabular}{|c|c|c|c|c|c|c|c|}
\hline & & $\begin{array}{r}\text { Hete } \\
\text { ak }\end{array}$ & $\begin{array}{l}\text { sigma } \\
\text { aiwo }\end{array}$ & $\begin{array}{r}\text { Alexc } \\
\text { mir }\end{array}$ & $\begin{array}{l}\text { Irium } \\
\text { um }\end{array}$ & $\begin{array}{r}\text { Karl } \\
\text { ven }\end{array}$ & $\begin{array}{l}\text { inium } \\
\text { cum }\end{array}$ \\
\hline & & Indoor & Outdoor & Indoor & Outdoor & Indoor & Outdoor \\
\hline & bcPBR & 30.60 & 39.60 & 32.15 & 36.50 & 32.15 & 37.98 \\
\hline & $\begin{array}{l}\text { Filling and } \\
\text { culture }\end{array}$ & & & & & & \\
\hline & Filling (water & 0.13 & 0.17 & 0.13 & 0.16 & 0.13 & 0.17 \\
\hline & Filling & 0.24 & 0.31 & 0.26 & 0.29 & 0.25 & 0.31 \\
\hline & $\begin{array}{r}\text { (seawater) } \\
\text { Culture }\end{array}$ & 0.26 & 0.30 & 0.34 & 0.32 & 0.27 & 034 \\
\hline Input & $\begin{array}{l}\text { Growing of } \\
\text { microalgae }\end{array}$ & & & & & & \\
\hline$\left(\mathrm{MJkg}^{-1}\right)$ & Chamber & 598.37 & 0.00 & 633.87 & 0.00 & 623.30 & 0.00 \\
\hline & Air pump & 73.47 & 94.98 & 77.83 & 89.17 & 76.54 & 93.72 \\
\hline & Fluorescents & 158.09 & 0.00 & 167.47 & 0.00 & 164.68 & 0.00 \\
\hline & $\begin{array}{l}\text { Dewatering } \\
\text { Centrifuge }\end{array}$ & 6.21 & 8.00 & 6.57 & 7.53 & 6.46 & 7.92 \\
\hline & Maintenance & & & & & & \\
\hline & $\begin{array}{r}\text { Washing } \\
\text { pump }\end{array}$ & 2.80 & 3.61 & 2.97 & 3.40 & 2.92 & 3.57 \\
\hline & Water & 0.31 & 0.40 & 0.32 & 0.37 & 0.32 & 0.39 \\
\hline & Total & 872 & 148 & 923 & 139 & 908 & 146 \\
\hline $\begin{array}{c}\text { Output } \\
\left(\mathrm{MJkg}^{-1}\right)\end{array}$ & & 8.78 & 8.78 & 8.78 & 8.78 & 8.78 & 8.78 \\
\hline $\begin{array}{l}\text { Balance } \\
\left(\mathrm{MJkg}^{-1}\right)\end{array}$ & & -863 & -139 & -914 & -130 & -899 & -137 \\
\hline
\end{tabular}


Table 2. Environmental impacts for microalgal species and impact category. Abiotic depletion (AD); acidification (A), eutrophication (E), global warming potential (GWP); ozone layer depletion (ODP); human toxicity (HT); freshwater aquatic ecotoxicity (FWAE); marine aquatic ecotoxicity (MAE); terrestrial ecotoxicity (TE) and photochemical oxidation (PO)

\begin{tabular}{|c|c|c|c|c|c|c|}
\hline \multirow{2}{*}{ Impact category (Eq. Units) } & \multicolumn{2}{|c|}{ Heterosigma akashiwo } & \multicolumn{2}{|c|}{ Alexandrium minutum } & \multicolumn{2}{|c|}{ Karlodinium veneficum } \\
\hline & Indoors & Outdoors & Indoors & Outdoors & Indoors & Outdoors \\
\hline A.D (kg SB eq.) & $1.06 \mathrm{E}+00$ & $1.75 \mathrm{E}-01$ & $1.12 \mathrm{E}+00$ & $1.69 \mathrm{E}-01$ & $1.10 \mathrm{E}+00$ & $1.73 \mathrm{E}-01$ \\
\hline A.C ( $\left(\mathrm{kg} \mathrm{SO}_{2}\right.$ eq. $)$ & $1.36 \mathrm{E}-00$ & $2.01 \mathrm{E}-01$ & $1.44 \mathrm{E}+00$ & $1.94 \mathrm{E}-01$ & $1.42 \mathrm{E}+00$ & $1.99 \mathrm{E}-01$ \\
\hline $\mathrm{E}$ (kg $\mathrm{PO}_{4}$ eq.) & 7.02E-02 & $1.14 \mathrm{E}-02$ & 7.45E-02 & $1.09 \mathrm{E}-02$ & 7.32E-02 & $1.13 \mathrm{E}-02$ \\
\hline GWP (kg CO2 eq.) & $1.44 \mathrm{E}+02$ & $2.38 \mathrm{E}+01$ & $1.53 \mathrm{E}+02$ & $2.29 \mathrm{E}+01$ & $1.51 \mathrm{E}+02$ & $2.35 \mathrm{E}+01$ \\
\hline ODP (kg CFC-11eq.) & 7.59E-06 & $9.82 \mathrm{E}-07$ & $8.66 \mathrm{E}-06$ & $1.63 \mathrm{E}-06$ & 7.99E-06 & $9.72 \mathrm{E}-07$ \\
\hline HT (kg 1,4-DB eq.) & $4.29 \mathrm{E}+01$ & $5.82 \mathrm{E}+00$ & $4.56 \mathrm{E}+01$ & $5.64 \mathrm{E}+00$ & $4.47 \mathrm{E}+01$ & $5.77 \mathrm{E}+00$ \\
\hline FWAE (kg 1,4-DB eq.) & $9.57 \mathrm{E}+00$ & $1.35 \mathrm{E}+00$ & $1.02 \mathrm{E}+01$ & $1.30 \mathrm{E}+00$ & $9.97 \mathrm{E}+00$ & $1.33 \mathrm{E}+00$ \\
\hline MAE (kg 1,4-DB eq.) & $2.42 \mathrm{E}+04$ & $3.19 \mathrm{E}+03$ & $2.57 \mathrm{E}+04$ & $3.11 \mathrm{E}+03$ & $2.52 \mathrm{E}+04$ & $3.16 \mathrm{E}+03$ \\
\hline TE (kg 1,4-DB eq.) & $2.41 \mathrm{E}-00$ & $3.10 \mathrm{E}-01$ & $2.56 \mathrm{E}+00$ & $3.04 \mathrm{E}-01$ & $2.51 \mathrm{E}+00$ & 3.07E-01 \\
\hline $\mathrm{PO}\left(\mathrm{kg} \mathrm{C}_{2} \mathrm{H}_{4}\right.$ eq. $)$ & $5.05 \mathrm{E}-02$ & 7.74E-03 & 5.37E-02 & 7.47E-03 & $5.27 \mathrm{E}-02$ & 7.65E-03 \\
\hline
\end{tabular}


Table 5: Sensitivity analysis after modifying energy consumption and lipid content for scenarios A, B, C, D and E

$$
\mathrm{MJ} \mathrm{kg}^{-1} \text { input } \quad \mathrm{MJ} \mathrm{kg}^{-1} \text { output } \quad \mathrm{MJ} \mathrm{kg}^{-1} \text { Balance }
$$

Scenario A

139

$-130$

Scenario B

69

12

$-57$

Scenario C

35

16

$-19$

Scenario D

17

19

2

Scenario E

9

23

14 
Table 6: Schemes of various LCA studies of bioenergy from microalgae

\begin{tabular}{|c|c|c|c|c|c|c|}
\hline \multirow{2}{*}{ Author } & \multirow{2}{*}{ Microalgae } & \multirow{2}{*}{ Reactor } & \multicolumn{3}{|c|}{ E. consumption $\left(\mathrm{MJkg}^{-1}\right)$} & \multirow[t]{2}{*}{ Balance } \\
\hline & & & Reactor & Growing & Dewatering & \\
\hline Razon et al. (2011)[37] & $\begin{array}{c}\text { Haematococcus pluvialis (freshwater) } \\
\text { Nannochloropsis sp (seawater) }\end{array}$ & $\begin{array}{l}\text { PBR + raceway pond } \\
\text { Raceway pond }\end{array}$ & $\begin{array}{l}- \\
-\end{array}$ & $\begin{array}{c}83.1 \\
151\end{array}$ & $\begin{array}{c}17 \\
-\end{array}$ & $\begin{array}{l}-134 \\
-465\end{array}$ \\
\hline Jorquera et al. (2010)[38] & $\begin{array}{l}\text { Nannochloropsis sp (seawater) } \\
\text { Nannochloropsis sp (seawater) } \\
\text { Nannochloropsis sp (seawater) }\end{array}$ & $\begin{array}{l}\text { Raceway pond } \\
\text { Flat-plate PBR } \\
\text { Tubular PBR }\end{array}$ & $\begin{array}{c}4.5 \mathrm{a} \\
7.3 \mathrm{a} \\
-\end{array}$ & $\begin{array}{c}3.8 \mathrm{~b} \\
7.0 \mathrm{~b} \\
159.0 \mathrm{~b}\end{array}$ & $\begin{array}{l}- \\
- \\
-\end{array}$ & $\begin{array}{c}23.3(\mathrm{a}+\mathrm{b}) / 27.7 \mathrm{~b} \\
17.3(\mathrm{a}+\mathrm{b}) / 24.6 \mathrm{~b} \\
-127 \mathrm{~b}\end{array}$ \\
\hline Sander et al. (2010)[39] & - & $\begin{array}{l}\text { PBR and raceway } \\
\text { pond }\end{array}$ & - & 0.1 & 53.9 & -49 \\
\hline Xu et al. (2011)[40] & Chlorella vulgaris (freshwater) & $\begin{array}{l}\text { Open pond dry route } \\
\text { Open pond wet route }\end{array}$ & $\begin{array}{l}0.8 \\
1.0\end{array}$ & $\begin{array}{l}3.3 \\
2.2\end{array}$ & $\begin{array}{l}4.7 \\
0.40\end{array}$ & $\begin{array}{l}-5.2 \\
-5.8\end{array}$ \\
\hline This work & Alenxandrium minutum (seawater) & bcPBR & 36.5 & 89.17 & 7.53 & -130 \\
\hline
\end{tabular}

${ }^{\mathrm{a}}$ Energy required for reactors production

${ }^{\mathrm{b}}$ Only included the energy consumption required for air pumping 

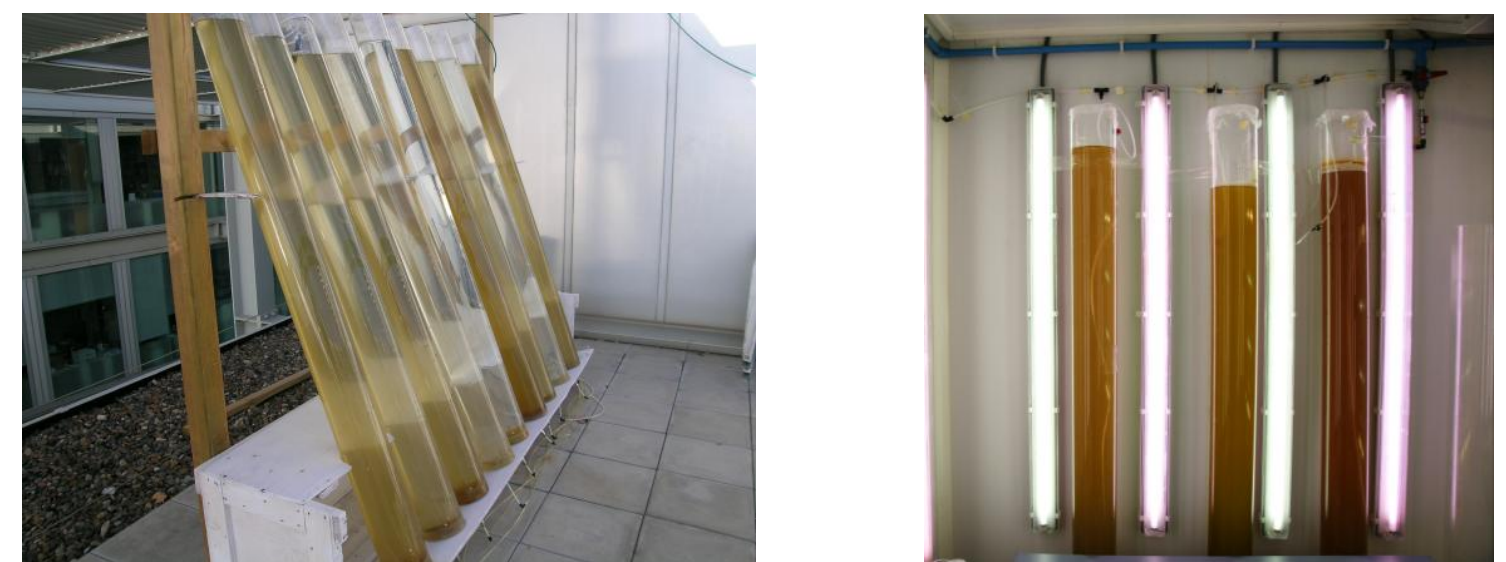

Figure 1. Photograph of the bubble column photobioreactor (bcPBR) under outdoor (left) and indoor (right) conditions. 


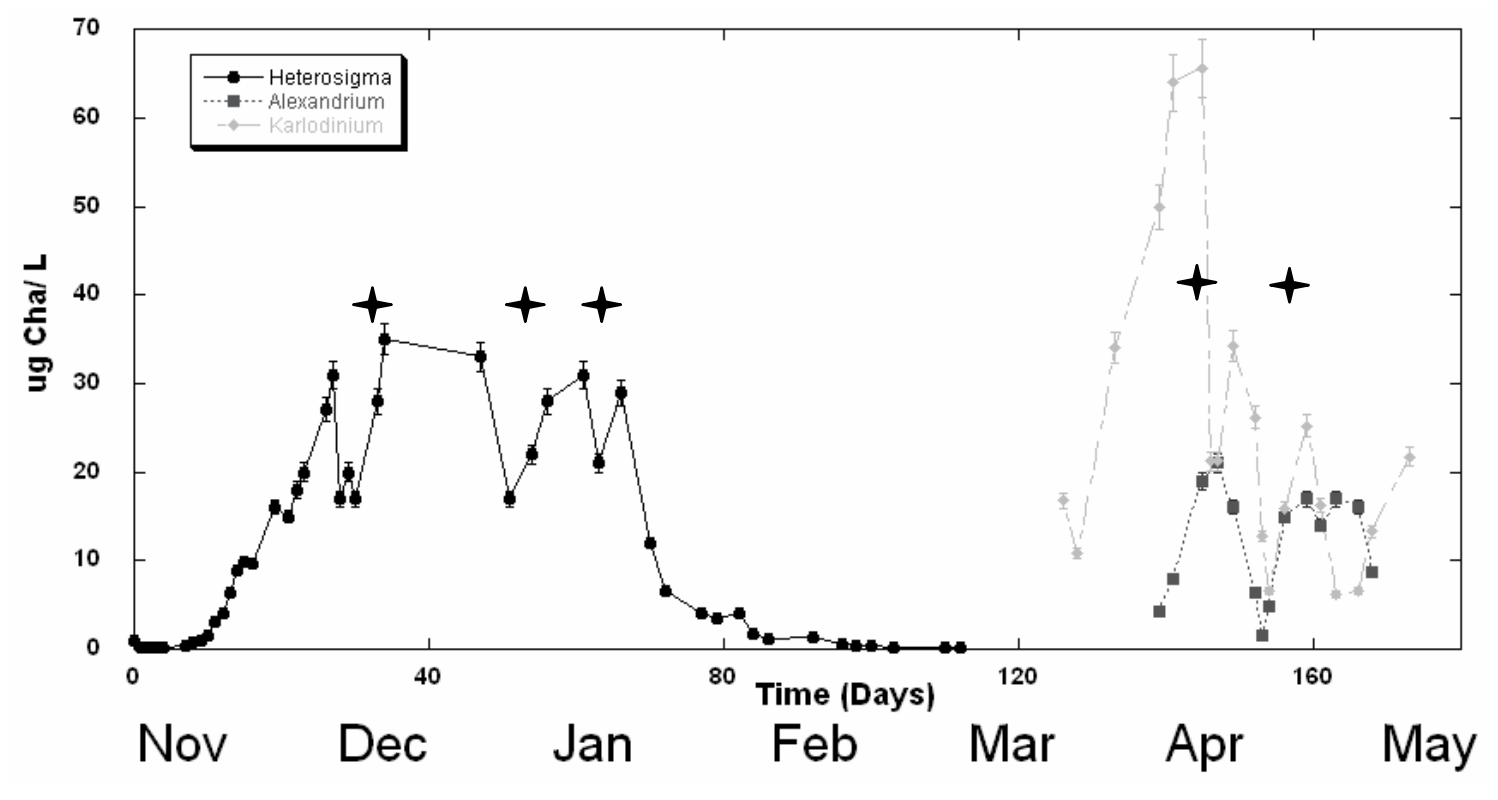

Figure 2: Growth curve of the different microalgae tested under outdoor conditions. + Indicates the harvest time of the culture. 


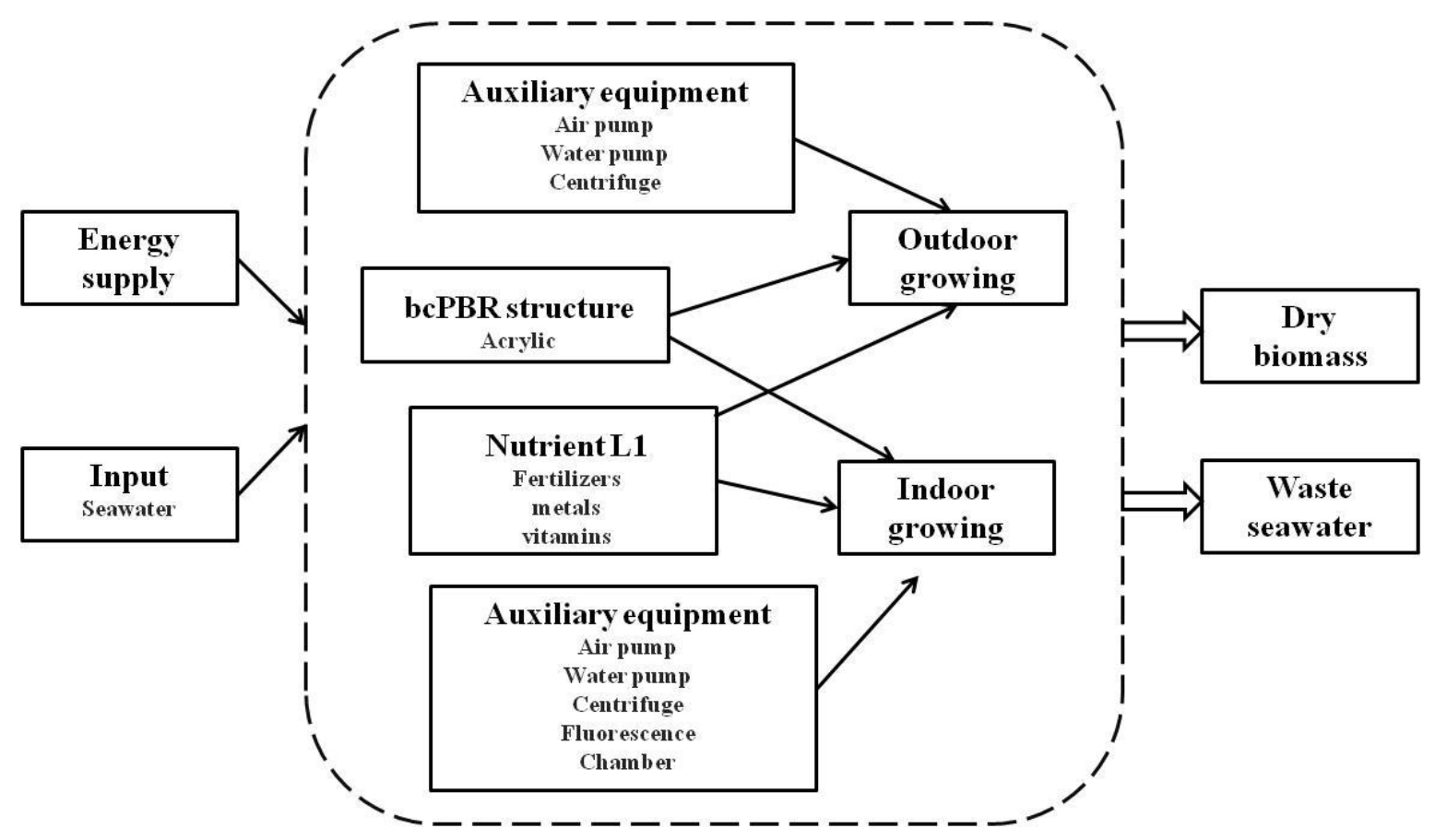

Figure 3: Life cycle system of microalgal biomass production for biodiesel production 


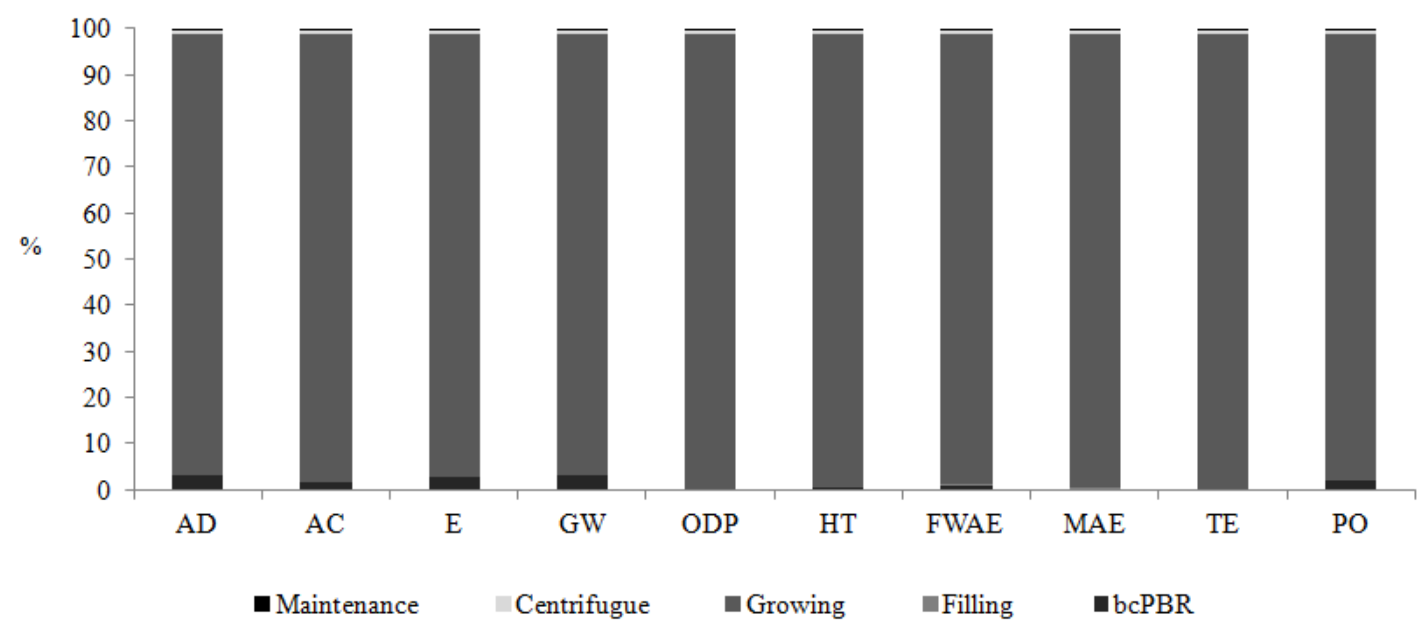

Figure 4: Relative contributions of different life stages of $A$. minutum under indoor conditions. 


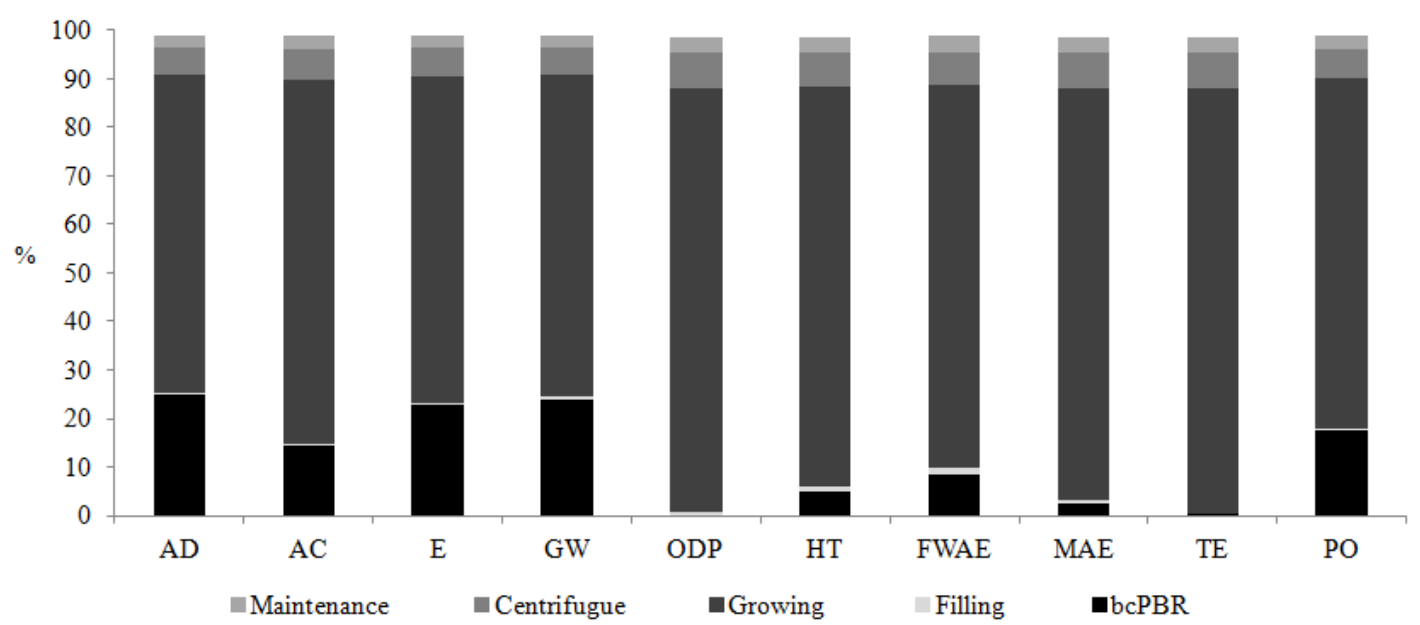

Figure 5: Relative contribution of different life cycle stages of $H$. akashiwo under outdoor conditions. 


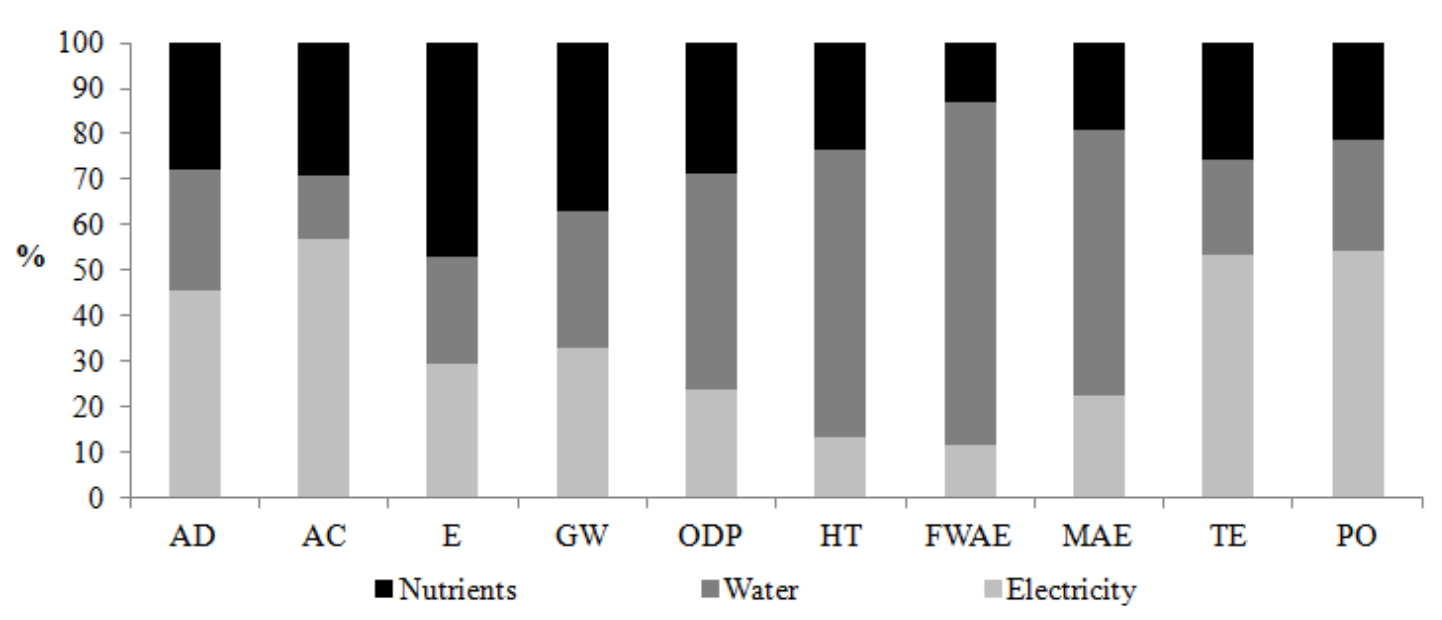

Figure 6. Relative contribution of electricity, water and L1 culture consumption of $H$. akashiwo under the outdoor conditions during the filling stage 